Nanoparticles for convective heat Transfer enhancement: heat transfer coefficient and the

\title{
effects of particle size and zeta potential
}

Lande Liu ${ }^{1 *}$, Viacheslav Stetsyuk ${ }^{2}$, Krzystof J. Kubiak², Yit Fatt Yap ${ }^{3}$, Afshin Goharzadeh ${ }^{3}$, John C.

$$
\text { Chai }^{2}
$$

${ }^{1}$ School of Applied Sciences, University of Huddersfield, Huddersfield, HD1 3DH, UK

${ }^{2}$ School of Computing and Engineering, University of Huddersfield, Huddersfield, HD1 3DH, UK

${ }^{3}$ Department of Mechanical Engineering, Khalifa University of Science and Technology, Petroleum Institute, P.O. Box 2533, Abu Dhabi, UAE

\begin{abstract}
This work presents a study of using the Wilson Plot method to determine the convective heat transfer coefficient (CHTC) of the following nanoparticles in water as the base fluid: $\mathrm{SiO}_{2}, \mathrm{TiO}_{2}$ and $\mathrm{Al}_{2} \mathrm{O}_{3}$. The experiments were carried out in a double layer concentric glass tube in which the hot fluid and nanofluids exchange heat in a counter current fashion without direct contact. Attention was also given to the volumetric concentration, flow rate and the size of nanoparticles to investigate their effects on CHTC. From the experiments, it was found that by adding nanoparticles, the CHTC of water can generally be enhanced and a $45 \%$ increase has been achieved with a 0.5 vol\% concentration of $\mathrm{Al}_{2} \mathrm{O}_{3}$ nanoparticles at an intermediate Reynolds number around 4100. Moreover, simply reducing nanoparticle size and increasing the nanofluid flow rate do not necessarily lead to the CHTC enhancement, rather, they have adverse effects. It is concluded that the enhancement depends on the stability of the dispersed nanoparticles that can be characterised by their overall mean size and zeta potential as useful measures.
\end{abstract}

Keywords: Convective heat transfer coefficient; Nanofluids; Nanoparticle heat transfer enhancement; Nanoparticles; Wilson plot; Zeta potential

\footnotetext{
*Corresponding author: 1.liu@ @ud.ac.uk
} 


\section{Introduction}

Nanofluids are often referred to those low concentration (less than 1.0 vol\%) colloidal dispersions with nanoparticles having at least one principal dimension within the range of 1-100 nm suspended in base fluids (usually water). It has been demonstrated that they have the potential to enhance heat transfer (Angayarkanni and Philip, 2015; Buongiorno and $\mathrm{Hu}, 2005$ ). However, it has been recognised that there are still knowledge gaps that hindered their application in industry (Buongiorno, 2006), for instance, in a fundamental level, how the enhancement mechanism was taking place still remains unclear and how the stability of the nanoparticles can be maintained to prevent them from aggregation is also an extremely challenging issue.

It has to be said that extensive study has long been given to the thermal conductivity enhancement of nanofluids (Angayarkanni and Philip, 2015; Eastman et al., 2004; Poulikakos et al., 2003; Prasher et al., 2005; Sarviya and Fuskele, 2017) as it is one of the most important properties of materials. More recently, the scope of nanofluid for heat transfer study has been widen in terms of material and process specifications (Hemmat Esfe et al., 2015; Toghraie et al., 2016b) and become more numerical (Esfahani and Toghraie, 2017). For instance, a study on the thermal conductivity of $\mathrm{MgO} / \mathrm{ethylene}$ glycol nanofluids on various temperatures and volume concentrations has been conducted using the neural network approach (Hemmat Esfe et al., 2014). It has been concluded that this method is useful in establishing correlations to predict the thermal conductivity of nanofluids with regard to temperature, volume concentration and particle size. Similar studies can also be found in these articles (Afrand et al., 2016; Hemmat Esfe et al., 2016b).

Experimental measurements and empirical modelling have also been sought in the attempt to establish the relationship between the theromal conductivity and the processing conditions such as temperature and volume fraction of the particles as seen in these articles (Esfahani and Toghraie, 2017; Toghraie et al., 2016b). Research has also been performed with the use of hybrid nanoparticles (Esfahani et al., 2018; Toghraie et al., 2016b; Zadkhast et al., 2017). The overall conclusion from these studies showed that the thermal conductivity of the nanofluid increases with the temperature and is more noticeable at higher solid concentrations. 
Additionally, it is interesting to say due to the lack of the understanding of the behaviour of nanoparticles in fluids, some contradicting results have also been seen in publications. Buongiorno et al. (2009) and Venerus et al. (2010) had their respective publications on the measurements of nanofluids' thermal conductivity and the viscosity of colloidal dispersions also for heat transfer. The data presented in their results were collected from some laboratories around the world. They showed that spherical nanoparticle fluids had lower thermal conductivity enhancement compared to those made of rod-shaped nanoparticles. In a more general sense, it was indicated that adding nanoparticles did not necessarily have a positive impact on the heat transfer of the base fluids. However, the work carried out by Khanafer and Vafai (2011) demonstrated an disagreement to the results of thermal conductivity and viscosity of nanofluids obtained by others. They also implied that in terms of modelling for the thermal conductivity and viscosity (Colangelo et al., 2016) of nanofluids, temperature should be recognised as playing an important role.

The study of viscosity of particle suspensions has long been an interesting area (Brinkman, 1952; Masuda et al., 1993; Prasher et al., 2006). Onto nanofluids, more recently, a study by (Hemmat Esfe et al., 2016a) showed that in alumina-engine oil nanofluids, the dynamic viscosity increases with the volume fraction of the solid particles but decreases with the increase in temperature which was more tangible for lower temperatures. It is also interesting to see that, some viscosity studies on the nanofluids containing magnetic nanopaticles have been carried out. The experimental results of the Fe/water nanofluids (Hemmat Esfe et al., 2015) have shown that the dynamic viscosity increases with the increases of Fe nanoparticles' concentration and diameter. It was also found in the study of Toghraie et al. (2016a) for $\mathrm{Fe}_{3} \mathrm{O}_{4} /$ water nanofluids the similar trend for the solid volume fraction but temperature had a negative effect, $i$. $e$, increasing temperature reduces viscosity.

While much work has been carried out on the experimental investigation and modelling of the thermal conductivity of the nanofluids (Nan et al., 1997; Pryazhnikov et al., 2017; Sarviya and Fuskele, 2017; Wang et al., 1999; Xuan and Li, 2000; Xue, 2003), it is thought that the industries are much interested in the convective heat transfer properties of nanofluids in practice (Kakaç and 
Pramuanjaroenkij, 2009; Sheikholeslami and Ganji, 2016; Xuan and Li, 2003). Nevertheless, some research studies have been devoted into this area. For instance, numerical simulations of the laminar flow of $\mathrm{CuO} /$ Water nanofluids in sinusoidal (Nazari and Toghraie, 2017) and triangular tubes (Aghanajafi et al., 2017) for their convective heat transfer have been made. Results showed that porous medium in the channel as well as adding nanoparticles into base fluids led to the increase of CHTC. This was said to be due to the reduction of temperature different in the porous regions. The authors also found that triangular tube simulation, the effect of particle size on CHTC was insignificant.

In addition to the Newtonian flow, studies on non-Newtonian nanofluids for convection heat transfer have also been carried out. In the study of Akbari et al. (2017), carboxy methyl cellulose solution in water with alumina as the nanoparticles was investigated. Their results showed that increasing the volume fraction of the solid nanoparticles and reducing the diameter of the nanoparticles improved the convective heat transfer and they have a more significant effect than changing the Reynolds number. Also in a numerical study of Sajadifar et al. (2017), the authors used similar mixture (aqueous solution of carboxymethyl cellulose with alumina nanoparticles) but for its flow through a microtube. Their results showed that higher volume fractions of nanoparticles and slip coefficients resulted in higher Nusselt numbers especially at larger Reynolds numbers.

This article is set out in such a way to investigate the CHTC of nanoparticles in aqueous suspensions. An experimental rig - a double layer concentric glass tube (annulus) in which the hot fluid and nanofluids exchange heat in a counter current fashion without a direct contact was designed and manufactured, with the inlet and outlet temperatures of the two fluids are measured in real time, the heat flux can then be calculated. To turn the heat flux into the CHTC of the nanofluids, a so-called Wilson Plot method (Wilson, 1915) was used to determine quantitatively the CHTC. The suspensions of $\mathrm{SiO}_{2}, \mathrm{TiO}_{2}$ and $\mathrm{Al}_{2} \mathrm{O}_{3}$ nanoparticles have been used and the size and zeta potential of these particles in the base fluid have also been measured in order to establish a quantitative relationship between the CHTC and these major material and process characteristics. 


\section{The experimental method, materials and nanofluids preparation}

Figure 1 shows the experimental rig constructed to study the convective heat transfer of the nanofluids. As can be seen from this figure, the nanofluid, driven by a pump (Eheim 1005 centrifugal pump), flows in the centre tube of the heat exchanger. The rig also consists of a reservoir tank (a one litre glass beaker) put in ultrasound sonication (Clifton Range, DU-8 heated digital) for breaking possible aggregates of the nanoparticles, a hot water bath (CW-05G, Jeio Tech Lab Companion) to provide hot water circulation in the jacket of the heat exchanger and a PC connected to a Pico PT-104 data logger for the acquisition of temperature data from the sensing probes ( $\mathrm{K}$ type thermocouples) attached to the inlets and outlets of the centre and jacket tubes.

(Figure 1)

The temperature of the hot water in circulation provided by the water bath was $70{ }^{\circ} \mathrm{C}$. The flow rate of the nanofluids was controlled by the pump with a maximum flow rate of $270 \mathrm{~L} \mathrm{~h}^{-1}$. The heat exchanger is an annular glass tube of $34 \mathrm{~cm}$ long. The centre tube in this glass annulus has an inner and outer diameter at $18 \mathrm{~mm}$ and $20 \mathrm{~mm}$, respectively. The thermocouples were attached to the inlet and outlet of the jacket and centre tube respectively to measure these temperatures. Also, a stirrer was used to enhance the mixing of the nanoparticles in the base fluid. The outside jacket surface of the annular glass tube heat exchanger was also thermally insulated to prevent its heat loss to the ambient environment. To ensure a consistent measurement and that the temperature abnormality was kept at the minimum, for each nanofluid flow rate, 500 temperature data were collected for each measuring point. The layout of the temperature probes is shown in Figure 2.

\section{(Figure 2)}

The nano materials used for the experiments included silica (LUDOX SM-30 colloidal silica, $30 \mathrm{wt} \%$ aqueous suspension), titanium (IV) oxide (a mixture of rutile and anatase, 33-37 wt\% aqueous suspension) and aluminium (III) oxide nanopowder with original mean particle size specified to be $\sim 50 \mathrm{~nm}, \sim 21 \mathrm{~nm}$ and $\sim 13 \mathrm{~nm}$, respectively. They were purchased from SigmaAldrich Ltd. 
A series of volume concentrations of nanofluids were prepared, i. e., $0.1,0.5,1.0 \mathrm{vol} \%$. In order to prepare the nanofluids of desired volume concentrations, the already made nano suspensions or nano powder were mixed with a certain amount of water that was precisely calculated. The mixture was then left in the ultrasonic bath with a stirrer for 3-5 hours to ensure that a stable and consistent dispersion of nanoparticles was produced. The size and zeta potential of the prepared nanofluids were measured by Zetasizer Nano (Malvern Instruments Plc).

\section{The theoretical approach to calculate the convective heat transfer coefficient}

The heat transferred from the hot water to the nanofluid in the tube takes place in three stages:

1. Convection from the hot water to the outer surface of the centre tube.

2. Thermal conduction through the outer surface to the inner surface of the centre tube wall.

3. Convection from the inner surface of the centre tube wall to the nanofluid.

As the three stages are combined in series, the overall heat transfer coefficient $U\left(\mathrm{~W} \mathrm{~m}^{-2}{ }^{\circ} \mathrm{C}^{-1}\right)$ is expressed as:

$$
\frac{1}{U}=\frac{1}{h_{n}}+\frac{d_{i}}{d_{o} h_{h}}+\frac{d_{i}}{2 k} \ln \left(\frac{d_{o}}{d_{i}}\right)
$$

where $h_{n}\left(\mathrm{~W} \mathrm{~m}^{-2}{ }^{\circ} \mathrm{C}^{-1}\right)$ and $h_{h}\left(\mathrm{~W} \mathrm{~m}^{-2}{ }^{\circ} \mathrm{C}^{-1}\right)$ are the CHTCs of the nanofluid and hot water, respectively. $k$ ( $\mathrm{W} \mathrm{m}^{-1}{ }^{\circ} \mathrm{C}^{-1}$ ) is the thermal conductivity of the centre tube wall. $d_{o}(\mathrm{~m})$ and $d_{i}(\mathrm{~m})$ are the outer and inner diameters of the centre tube wall, respectively. $L(\mathrm{~m})$ is the length of the centre tube.

In Eq. (1), the first term on the right hand side accounts for the contribution from the convective heat transfer of the nanofluid corresponding to Stage 3. The second is attributed to the convective heat transfer of the hot water where the ratio of $d_{i}$ to $d_{o}$ accounts for the effect of area difference between the inner and outer surfaces of the centre tube. This term corresponds to Stage 1. The third term of the right hand side of Eq. (1) is contributed from the conduction of the wall of the centre tube and the factor $\ln \left(d_{o} / d_{i}\right)$ accounts for the difference between the outer and inner diameters of the centre tube wall and this term is corresponding to Stage 2. 
Wilson (Wilson, 1915) used the fact that for turbulent flow conditions the CHTC varies with the fluid velocity $V\left(\mathrm{~m} \mathrm{~s}^{-1}\right)$ and may be approximately written as:

$$
h_{n}=c V^{0.8}
$$

where $c$ is a constant. The purpose of Eq. (2) is to replace $h_{n}$ of Eq. (1) with $c V^{0.8}$ so a direct relationship between $1 / U$ and $V^{0.8}$ can be established as detailed below.

It is worth pointing out that Eq. (2) should be ideally applied to turbulent flow. Nevertheless, due to the limiting capacity of the pump, the flow of nanofluids in this experiment may occur in laminar flow conditions. However, it was thought (Debab et al., 2011) that the only difference to use Eq. (2) for laminar flow was the power index of the velocity so according to Eq. (1), the trend of $h_{n}$ in flow rate in laminar region would not change.

Substituting Eq. (2) into Eq. (1) yields:

$$
\frac{1}{U}=\frac{1}{c V^{0.8}}+\frac{d_{i}}{d_{o} h_{h}}+\frac{d_{i}}{2 k} \ln \left(\frac{d_{o}}{d_{i}}\right)
$$

If the hot water flow in the jacket of the concentric pipe is not changed, then $h_{h}$ can be regarded as a constant so the plot of $1 / U$ against $1 / V^{0.8}$ is expected to result in a straight line with its gradient being $1 / c$. In such cases, $c$ is then calculated.

The rate of heat transfer due to the loss of heat from the hot water is:

$$
Q=W c_{p}\left(T_{h i}-T_{h o}\right)
$$

where $W\left(\mathrm{~kg} \mathrm{~s}^{-1}\right)$ is the hot water flow rate and $c_{p}\left(\mathrm{~J} \mathrm{~kg}^{-1}{ }^{\circ} \mathrm{C}^{-1}\right)$ is the specific heat capacity of the hot water. This rate of heat transfer can also be calculated using the overall heat transfer coefficient $U$ and the logarithmic mean temperature difference $\Delta T_{m}\left({ }^{\circ} \mathrm{C}\right)$ between the hot water and the nanofluid:

$$
Q=U \pi d_{o} L \Delta T_{m}
$$

where $L(\mathrm{~m})$ is the length of the bube and $\Delta T_{m}$ is given by:

$$
\Delta T_{m}=\frac{\left(T_{h i}-T_{n o}\right)-\left(T_{h o}-T_{n i}\right)}{\ln \left(\frac{T_{h i}-T_{n o}}{T_{h o}-T_{n i}}\right)}
$$


Using Eq. (4), the rate of heat transfer can be calculated, substituting this value into Eq. (5), the overall heat transfer coefficient can then be calculated. Also, the velocity of nanofluid $V$ is calculated from the volumetric flow rate of the pump. By plotting $1 / U$ vs $1 / N^{0.8}, c$ can be determined. Use the value of $c$ the CHTC of the nanofluid $h_{n}$ can be calculated. It should be mentioned that the calculation of $U$ depends on the expermimental measurement of temperatures of the hot water and nanofluid at their inlets and outlets. As 500 temperature data for each nanofluid flow rate at each measuring point were collected, the final $1 / U$ value used in the plot against $1 / N^{0.8}$ is the one that was averaged from those $500 U$ values.

\section{Results and discussion}

Figure 3 shows the plots of $1 / U$ vs $1 / V^{0.8}$ for the suspensions of $\mathrm{SiO}_{2}$ nanofluids at volume concentrations of $0.1 \%, 0.5 \%$ and $1.0 \%$ and the base fluid (deionised water).

(Figure 3)

Combining those linear fittings in Figure 3 together, a comparison between them is made in Figure 4.

(Figure 4)

As can be seen from Figure 4, the 4 straight lines are largely parallel to each other indicating similar slopes that they have similar CHTCs. This is presented in Figure 5(a) as against the Reynolds number of the nanofluid. The Reynolds number of the nanofluid is defined as $\operatorname{Re}=\rho V d_{i} / \mu$ where $\rho\left(\mathrm{kg} \mathrm{m}^{-3}\right), V\left(\mathrm{~m} \mathrm{~s}^{-1}\right)$ and $\mu(\mathrm{Pa} \mathrm{s})$ are the density, velocity and dynamic viscosity of the nanofluid flowing in the centre tube. $\mu$ has taken the concentration of the nanoparticles into consideration using Einstein's equation $\mu=\mu_{w}(1+2.5 \phi)$ (Einstein, 1906) in which $\mu_{w}$ (Pa s) is the viscosity of water and $\phi(-)$ is the volume fraction of the nanoparticles. The percentage of the change of the $\mathrm{CHTC}$ of $\mathrm{SiO}_{2}$ nanofluids from that of water is shown in Figure 5(b).

(Figure 5)

As seen from Figure 5(a), there is a general increase of the CHTC in the Reynolds number of the fluid. However, from Figure 5 (b), the percentage of $\mathrm{SiO}_{2}$ nanofluid CHTC increase to water is not consistent. In fact, there is a decrease of CHTC for $0.1 \mathrm{vol} \% \mathrm{SiO}_{2}$ nanofluid compared to that of 
water at low Reynolds numbers and the similar trend was found for the concentration of 1.0 vol\%. This is likely due to the stability of those nanofluids that has changed during dilution and a size and zeta potential analysis could confirm this as seen in Figure 10. The largest enhancement that has been seen from those $\mathrm{SiO}_{2}$ nanofluids in this experiment comes from the concentration of 0.5 vol\% which had approximately an $18 \%$ increase in a relatively low Reynolds number around 4000. Interestingly, larger Reynolds numbers did not seem to promote further increase of CHTC for those $\mathrm{SiO}_{2}$ nanofluids. Again, this may be due to the stability of nanoparticles changed during the mixing in the vessel and circulation in the pipe.

Graphs in Figure 6 are the results of the linear fittings of $1 / U$ vs $1 / V^{0.8}$ for $\mathrm{TiO}_{2}$ nanofluids at $0.1 \mathrm{vol} \%, 0.5 \mathrm{vol} \%$ and $1.0 \mathrm{vol} \%$, the graph on the bottom right is the comparison of these linear fittings.

(Figure 6)

As seen in Figure 6, the fitting for $1.0 \mathrm{vol}^{\circ} \mathrm{TiO}_{2}$ nanofluid had a large error which implies a stability issue but the ones for 0.1 vol\% and 0.5 vol\% concentrations are generally good. The Comparison of these fittings on the bottom right of Figure 6 has also elaborated this.

(Figure 7)

As seen clearly from Figure 7(a), a general trend of CHTC increasing with the Reynolds number of the fluids has been seen and also the higher concentrations of the $\mathrm{TiO}_{2}$ nanoparticles, the better the CHTC would be as illustrated in Figure 7(b). However, caution should be taken when dealing with the CHTC data for 1.0 vol\% $\mathrm{TiO}_{2}$ nanofluid as its linear fitting has the point with the lowest Reynolds number neglected, rather the results for 0.1 vol\% and $0.5 \mathrm{vol} \% \mathrm{TiO}_{2}$ nanofluids are much more reliable. It is so that the CHTC enhancement of $\mathrm{TiO}_{2}$ nanoparticles in this experiment was made with an increase of $40 \%$ at concentration of $0.5 \%$ with Reynolds number around 4000 while at 1.0 vol\% the $\mathrm{TiO}_{2}$ nanoparticles had negative impact on the CHTC of the base fluid.

Figure 8 shows the results for $\mathrm{Al}_{2} \mathrm{O}_{3}$ nanofluids.

(Figure 8) 
Again, as seen in Figure 8, the fitting for $\mathrm{Al}_{2} \mathrm{O}_{3}$ nanofluids at $1.0 \mathrm{vol} \%$ has the point on the right (bottom left graph) neglected while with $0.5 \mathrm{vol} \%$ (top right graph), the point on the left was neglected, which indicated an issue of stability in these flow conditions, comparison of the fittings shows that water had highest gradient indicating an increase in $\mathrm{CHTC}$ when $\mathrm{Al}_{2} \mathrm{O}_{3}$ nanoparticles are added.

(Figure 9)

Figure 9 (a) showed a general increase of CHTC of the fluids in Reynolds number, again Figure 9 (b) demonstrated a concentration of 0.5 vol\% $\mathrm{Al}_{2} \mathrm{O}_{3}$ nanoparticles has made in majority the largest increase in CHTC while the highest enhancement of approximately $45 \%$ was achieved at the Reynolds number around 4000. It is worth mentioning that the high concentration $(\sim 1.0$ vol\%) results of the relative CHTC enhancement at low Reynolds numbers are comparable to that reviewed in the article of Kakaç and Pramuanjaroenkij (2009). Nevertheless, the deviations were seen at low concentrations and this can be attributed to the difference how the stability was maintained and how the low concentration nanofluids were prepared.

In summary, the above experimental results have demonstrated the following four important aspects in the area of nanoparticle enhancing heat transfer. 1) the Wilson Plot method can still be applied to laminar and transit flow regions for comparison and trend finding purpose, 2) nanoparticles can generally enhance the CHTC of the base fluid, 3) a larger Reynolds number does not necessary lead to a larger enhancement and 4) the main issue in CHTC enhancement by nanoparticles is the stability of the particles, mainly characterised by the size of the particles and the state of the dispersion of the particles.

Figure 10(a) shows the mean particle size for the $\mathrm{SiO}_{2}, \mathrm{TiO}_{2}$ and $\mathrm{Al}_{2} \mathrm{O}_{3}$ nanofluid samples at concentrations of $0.1 \mathrm{vol} \%, 0.5 \mathrm{vol} \%$ and $1.0 \mathrm{vol} \%$ and (b) is how the particle size change affects CHTC enhancement at Reynolds number 4100 as a typical example as other Reynolds numbers lead to the same trend.

(Figure 10) 
It is worth noting from Figure 10(a) with the increase of concentration, particle size generally decreases and all deviated from their reported original size. This may be due to aggregation of the particles caused by the process of dilution as dilution would normally reduce the magnitude of the zeta potential of the particles as shown in Figure 11(a) and consequently the stability of the nanoparticles in the base fluid thus the particles will become more aggregated, which is reflected in the overall size measurement shown in Figure 10(a). It is also interesting to see that in Figure 10(b), neither does the largest particle size nor the smallest result in the highest CHTC enhancement; it is in fact the one between them that gives the largest increase. This could be due to an optimum interdistance between the particles of clustering (aggregating) state that has been formed and demonstrates such particular overall sizes. An intensive discussion can be found in the publication of Liu (Liu, 2015). This in this article is also confirmed by the zeta potential measurement of the nanofluid samples used as shown in Figure 11(b).

\section{(Figure 11)}

It is clear from Figure 11 that for the three types of nanofluids studied, similar trend has been found for the change of nanoparticle size in the magnitude of zeta potential, i.e., as the value of zeta potential increases, the particle mean size decreases. Moreover, the mid value of the particle mean size for each type of the nanofluids appeared to correspond to a zeta potential that stands in the transition region of metastable state. This is particularly true for $\mathrm{SiO}_{2}$ and $\mathrm{Al}_{2} \mathrm{O}_{3}$ nanoparticles if a value of $\sim 30 \mathrm{mV}$ is taken to identify a stable state as discussed by Derjaguin many years ago (Derjaguin, 1940). It is also not surprising that the $\mathrm{Al}_{2} \mathrm{O}_{3}$ nanofluids have the highest CHTC enhancement, this is due to the facts that the magnitude of zeta potential is within the range of 20$30 \mathrm{mV}$ and their corresponding particle mean sizes are well below $100 \mathrm{~nm}$. So the underlying message from Figure 11 is that it is possible to control and optimise the enhancement of nanoparticles for CHTC by simply controlling the zeta potential of the nano suspension into the metastable region. Such quantitative correlations have the potential to open the possibility and guide the way to maximise the CHT enhancement. 


\section{Conclusion and Challenges}

The study carried out in this research confirms that adding $\mathrm{SiO}_{2}, \mathrm{TiO}_{2}$ and $\mathrm{Al}_{2} \mathrm{O}_{3}$ nanoparticles can generally enhance the CHTC of the base fluid (water in this case). A $45 \%$ enhancement was achieved with 0.5 vol\% $\mathrm{Al}_{2} \mathrm{O}_{3}$ nanoparticles. However, by how much such an enhancement can be made largely depends on the particle size and dispersion state of the particles. For the nanoparticles of the same type of material, smaller particles do not necessarily lead to a larger enhancement. Also larger Reynolds numbers do not necessarily result in a better convective heat transfer in nanofluids. The enhancement will depend on the clustering state and the stability as characterised by the overall size and zeta potential of the nanoparticles as the useful measures.

However, the challenge is thought to still remain in the fundamental level, that is, it was not clear how such an enhancement was taking place and how it can be theoretically calculated in terms of the properties of particles and the base fluid. While much effort has been made in the model development, this still remains as a real challenge as there is so far no general agreement to which model has its general applicability; and without such a fundamental understanding, nanofluids towards industrial applications for heat transfer enhancement will be significantly hindered. Nevertheless, before the theoretical breakthrough takes its stage, experimental methods and empirical correlations can still provide some insights into the behaviour of nanoparticles in the area of facilitating heat transfer through some quantitatively justifiable measures such as the overall size and zeta potential just as the research conducted in this article. This will also hopefully pave the way progressively towards a fundamental breakthrough in the near future. 


\section{References}

Afrand, M., Toghraie, D., Sina, N. (2016). Experimental study on thermal conductivity of waterbased Fe3O4 nanofluid: Development of a new correlation and modeled by artificial neural network. International Communications in Heat and Mass Transfer, 75, 262-269.

Aghanajafi, A., Toghraie, D., Mehmandoust, B. (2017). Numerical simulation of laminar forced convection of water-CuO nanofluid inside a triangular duct. Physica E: Low-dimensional Systems and Nanostructures, 85, 103-108.

Akbari, O.A., Toghraie, D., Karimipour, A., Marzban, A., Ahmadi, G.R. (2017). The effect of velocity and dimension of solid nanoparticles on heat transfer in non-Newtonian nanofluid. Physica E: Low-dimensional Systems and Nanostructures, 86, 68-75.

Angayarkanni, S.A., Philip, J. (2015). Review on thermal properties of nanofluids: Recent developments. Advances in Colloid and Interface Science, 225, 146-176.

Brinkman, H.C. (1952). The Viscosity of Concentrated Suspensions and Solutions. J. Chem. Phys., 20, 571-581.

Buongiorno, J. (2006). Convective Transport in Nanofluids. Transactions of the ASME, 128, 240250.

Buongiorno, J., Hu, L.-W. (2005). Nanofluid Coolants for Advanced Nuclear Power Plants, Proceedings of ICAPP '05, Seoul, May 15-19.

Buongiorno, J., Venerus, D.C., Prabhat, N., McKrell, T., Townsend, J., Christianson, R., Tolmachev, Y.V., Keblinski, P., Hu, L.-w., Alvarado, J.L., Bang, I.C., Bishnoi, S.W., Bonetti, M., Botz, F., Cecere, A., Chang, Y., Chen, G., Chen, H., Chung, S.J., Chyu, M.K., Das, S.K., Paola, R.D., Ding, Y., Dubois, F., Dzido, G., Eapen, J., Escher, W., Funfschilling, D., Galand, Q., Gao, J., Gharagozloo, P.E., Goodson, K.E., Gutierrez, J.G., Hong, H., Horton, M., Hwang, K.S., Iorio, C.S., Jang, S.P., Jarzebski, A.B., Jiang, Y., Jin, L., Kabelac, S., Kamath, A., Kedzierski, M.A., Kieng, L.G., Kim, C., Kim, J.-H., Kim, S., Lee, S.H., Leong, K.C., Manna, I., Michel, B., Ni, R., Patel, H.E., Philip, J., Poulikakos, D., Reynaud, C., Savino, R., Singh, P.K., Song, P., Sundararajan, T., Timofeeva, E., Tritcak, T., Turanov, A.N., Vaerenbergh, S.V., Wen, D., 
Witharana, S., Yang, C., Yeh, W.-H., Zhao, X.-Z., Zhou, S.-Q. (2009). A benchmark study on the thermal conductivity of nanofluids. Journal of Applied Physics, 106, 094312.

Colangelo, G., Favale, E., Miglietta, P., Milanese, M., de Risi, A. (2016). Thermal conductivity, viscosity and stability of A12O3-diathermic oil nanofluids for solar energy systems. Energy, 95, 124-136.

Debab, A., Chergui, N., Bekrentchir, K., Bertrand, J. (2011). An Investigation of Heat Transfer in a Mechanically Agitated Vessel. Journal of Applied Fluid Mechanics, 4, 43-50.

Derjaguin, B. (1940). On the repulsive forces between charged colloid particles and on the theory of slow coagulation and stability of lyophobe sols. Transactions of the Faraday Society, 35, 203215.

Eastman, J.A., Phillpot, S.R., Choi, S.U.S., Keblinski, P. (2004). Thermal Transport in Nanofluids. Annual Review of Materials Research, 34, 219-246.

Einstein, A. (1906). Eine neue Bestimmung der Moleküldimensionen. Annalen der Physik, 324, 289-306.

Esfahani, M.A., Toghraie, D. (2017). Experimental investigation for developing a new model for the thermal conductivity of Silica/Water-Ethylene glycol (40\%-60\%) nanofluid at different temperatures and solid volume fractions. Journal of Molecular Liquids, 232, 105-112.

Esfahani, N.N., Toghraie, D., Afrand, M. (2018). A new correlation for predicting the thermal conductivity of $\mathrm{ZnO}-\mathrm{Ag}(50 \%-50 \%) /$ water hybrid nanofluid: An experimental study. Powder Technology, 323, 367-373.

Hemmat Esfe, M., Afrand, M., Gharehkhani, S., Rostamian, H., Toghraie, D., Dahari, M. (2016a). An experimental study on viscosity of alumina-engine oil: Effects of temperature and nanoparticles concentration. International Communications in Heat and Mass Transfer, 76, 202208.

Hemmat Esfe, M., Saedodin, S., Bahiraei, M., Toghraie, D., Mahian, O., Wongwises, S. (2014). Thermal conductivity modeling of $\mathrm{MgO} / \mathrm{EG}$ nanofluids using experimental data and artificial neural network. Journal of Thermal Analysis and Calorimetry, 118, 287-294. 
Hemmat Esfe, M., Saedodin, S., Wongwises, S., Toghraie, D. (2015). An experimental study on the effect of diameter on thermal conductivity and dynamic viscosity of Fe/water nanofluids. Journal of Thermal Analysis and Calorimetry, 119, 1817-1824.

Hemmat Esfe, M., Yan, W.-M., Afrand, M., Sarraf, M., Toghraie, D., Dahari, M. (2016b). Estimation of thermal conductivity of Al2O3/water (40\%)-ethylene glycol (60\%) by artificial neural network and correlation using experimental data. International Communications in Heat and Mass Transfer, 74, 125-128.

Kakaç, S., Pramuanjaroenkij, A. (2009). Review of convective heat transfer enhancement with nanofluids. International Journal of Heat and Mass Transfer, 52, 3187-3196.

Khanafer, K., Vafai, K. (2011). A critical synthesis of thermophysical characteristics of nanofluids. International Journal of Heat and Mass Transfer, 54, 4410-4428.

Liu, L. (2015). Aggregation of silica nanoparticles in an aqueous suspension. AIChE Journal, 61, 2136-2146.

Masuda, H., Ebata, A., Teramae, K., Hishinuma, N. (1993). Alteration of Thermal Conductivity and Viscosity of Liquid by Dispersing Ultra-Fine Particles. Netsu Bussei, 7, 227-233.

Nan, C.W., Birringer, R., Clarke, D.R., Gleiter, H. (1997). Effective thermal conductivity of particulate composites with interfacial thermal resistance. J. Appl. Phys., 81, 6692.

Nazari, S., Toghraie, D. (2017). Numerical simulation of heat transfer and fluid flow of Water-CuO Nanofluid in a sinusoidal channel with a porous medium. Physica E: Low-dimensional Systems and Nanostructures, 87, 134-140.

Poulikakos, D., Arcidiacono, S., Maruyama, S. (2003). Molecular dynamics simulations in nanoscale heat transfer: a review. Micro. Thermophys. Eng., 7, 181-206.

Prasher, R., Bhattacharya, P., Phelan, P.E. (2005). Thermal Conductivity of Nanoscale Colloidal Solutions (Nanofluids). Physical Review Letters, 94, 025901.

Prasher, R., Song, D., Wang, J. (2006). Measurements of nanofluid viscosity and its implications for thermal applications. Applied Physics Letters, 89, 133108. 
Pryazhnikov, M.I., Minakov, A.V., Rudyak, V.Y., Guzei, D.V. (2017). Thermal conductivity measurements of nanofluids. International Journal of Heat and Mass Transfer, 104, 1275-1282.

Sajadifar, S.A., Karimipour, A., Toghraie, D. (2017). Fluid flow and heat transfer of nonNewtonian nanofluid in a microtube considering slip velocity and temperature jump boundary conditions. European Journal of Mechanics - B/Fluids, 61, 25-32.

Sarviya, R.M., Fuskele, V. (2017). Review on Thermal Conductivity of Nanofluids. Materials Today: Proceedings, 4, 4022-4031.

Sheikholeslami, M., Ganji, D.D. (2016). Nanofluid convective heat transfer using semi analytical and numerical approaches: A review. Journal of the Taiwan Institute of Chemical Engineers, $\mathbf{6 5}$, 43-77.

Toghraie, D., Alempour, S.M., Afrand, M. (2016a). Experimental determination of viscosity of water based magnetite nanofluid for application in heating and cooling systems. Journal of Magnetism and Magnetic Materials, 417, 243-248.

Toghraie, D., Chaharsoghi, V.A., Afrand, M. (2016b). Measurement of thermal conductivity of ZnO-TiO2/EG hybrid nanofluid. Journal of Thermal Analysis and Calorimetry, 125, 527-535.

Venerus, D., Buongiorno, J., Christianson, R., Townsend, J., Bang, I.C., Chen, G., Chung, S.J., Chyu, M., Chen, H., Ding, Y., Dubois, F., Dzido, G., Funfschilling, D., Galand, Q., Gao, J., Hong, H., Horton, M., Hu, L., Iorio, C.s., Zhou, S.-Q. (2010). Viscosity measurement of colloidal dispersion (nanofluids) for heat transfer applications. Applied Rheology, 20, 44582.

Wang, X., Xu, X., Choi, S.U.S. (1999). Thermal conductivity of nanoparticles-fluid mixture. J. Thermophys. Heat Trans., 13, 474.

Wilson, E.E. (1915). A basis for rational design of heat transfer apparatus. Transactions of the American Society of Mechanical Engineers, 37, 47-70.

Xuan, Y., Li, Q. (2000). Heat transfer enhancement of nanofluids. International Journal of Heat and Fluid Flow, 21, 58-64.

Xuan, Y., Li, Q. (2003). Investigation on Convective Heat Transfer and Flow Features of Nanofluids. J. Heat Transfer, 125, 151-155. 
Xue, Q.Z. (2003). Model for effective thermal conductivity of nanofluids. Phys. Lett. A, 307, 313317.

Zadkhast, M., Toghraie, D., Karimipour, A. (2017). Developing a new correlation to estimate the thermal conductivity of MWCNT-CuO/water hybrid nanofluid via an experimental investigation. Journal of Thermal Analysis and Calorimetry, 129, 859-867. 


\section{Figure Captions}

Figure 1 Schematic diagram of the heat transfer and measurement system.

Figure 2 The measurement system of the heat exchanger. Note, $T_{n i}\left({ }^{\circ} \mathrm{C}\right)$ and $T_{n o}\left({ }^{\circ} \mathrm{C}\right)$ are the temperatures of the nanofluid at the inlet and outlet of the centre tube, respectively. Also, $T_{h i}\left({ }^{\circ} \mathrm{C}\right)$ and $T_{h o}\left({ }^{\circ} \mathrm{C}\right)$ are the temperatures of the hot water at the inlet and outlet of the jacket, respectively. $d_{i}(\mathrm{~m})$ and $d_{o}(\mathrm{~m})$ are the inner and outer diameters of the centre tube, respectively.

Figure 3 Plots of $1 / U$ vs $1 / V^{0.8}$ for $\mathrm{SiO}_{2}$ nanofluids and water. Note, the straight lines are the linear fittings to the experimental data points.

Figure 4 Comparison of the linear fittings of $1 / U$ vs $1 / V^{0.8}$ for $\mathrm{SiO}_{2}$ nanofluids and water.

Figure 5 (a) Calculated heat transfer coefficients for water and $\mathrm{SiO}_{2}$ nanofluids for different Reynolds numbers and (b) the percentage of the change of $\mathrm{CHTC}$ of $\mathrm{SiO}_{2}$ nanofluids to that of water.

Figure 6 The linear fittings of $1 / U$ vs $1 / V^{0.8}$ for $\mathrm{TiO}_{2}$ nanofluids at $0.1 \mathrm{vol} \%, 0.5 \mathrm{vol} \%$ and 1.0 vol\%, the graph on the bottom right is the comparison of these linear fittings.

Figure 7 (a) Calculated heat transfer coefficients for water and $\mathrm{TiO}_{2}$ nanofluids for different Reynolds numbers and (b) the percentage of the change of $\mathrm{CHTC}$ of $\mathrm{TiO}_{2}$ nanofluids to that of water.

Figure 8 The linear fittings of $1 / \mathrm{U}$ vs $1 / \mathrm{V}^{0.8}$ for $\mathrm{Al}_{2} \mathrm{O}_{3}$ nanofluids at 0.1 vol\%, 0.5 vol\% and 1.0 vol\%, the graph on the bottom right is the comparison of these linear fittings.

Figure 9 (a) Calculated heat transfer coefficients for water and $\mathrm{Al}_{2} \mathrm{O}_{3}$ nanofluids for different Reynolds numbers and (b) the percentage of the change of $\mathrm{CHTC}$ of $\mathrm{Al}_{2} \mathrm{O}_{3}$ nanofluids to that of water.

Figure 10 (a) Particle mean size vs concentration for $\mathrm{SiO}_{2}, \mathrm{TiO}_{2}$ and $\mathrm{Al}_{2} \mathrm{O}_{3}$ nanofluids and (b) the percentage of CHTC enhancement to water vs particle size at Reynolds number 4100.

Figure 11 Magnitude of zeta potential vs (a) concentration and (b) particle mean size of the nanofluid samples. 


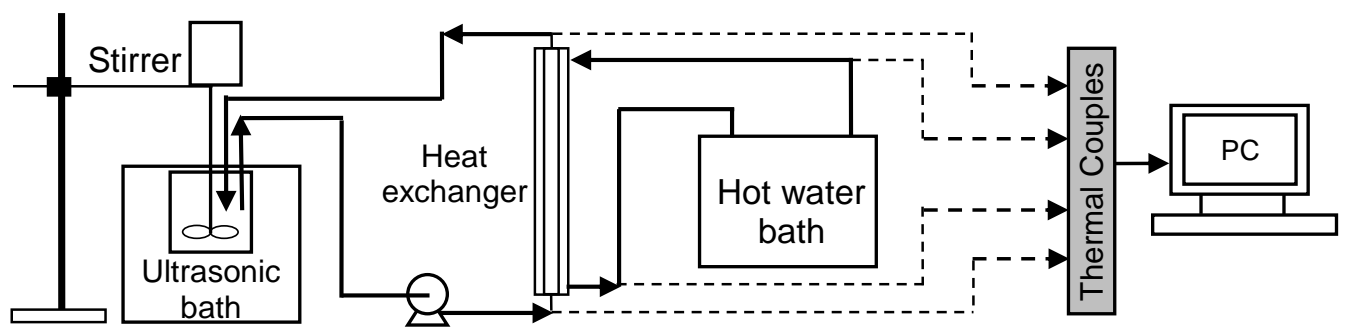

Figure 1 Schematic diagram of the heat transfer and measurement system. 


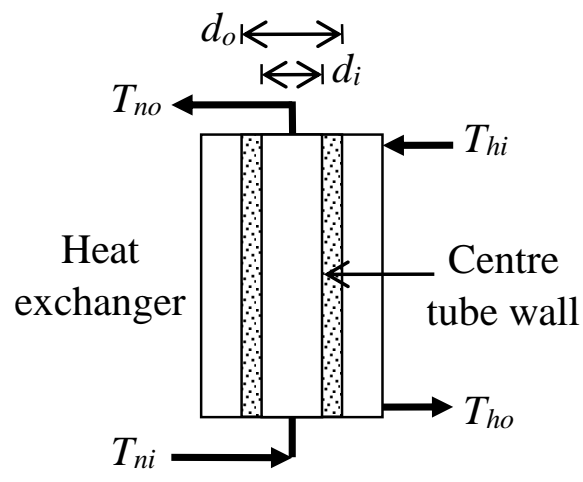

Figure 2 The measurement system of the heat exchanger. Note, $T_{n i}\left({ }^{\circ} \mathrm{C}\right)$ and $T_{n o}\left({ }^{\circ} \mathrm{C}\right)$ are the temperatures of the nanofluid at the inlet and outlet of the centre tube, respectively. Also, $T_{h i}\left({ }^{\circ} \mathrm{C}\right)$ and $T_{h o}\left({ }^{\circ} \mathrm{C}\right)$ are the temperatures of the hot water at the inlet and outlet of the jacket, respectively. $d_{i}(\mathrm{~m})$ and $d_{o}(\mathrm{~m})$ are the inside and outside diameters of the centre tube, respectively. 

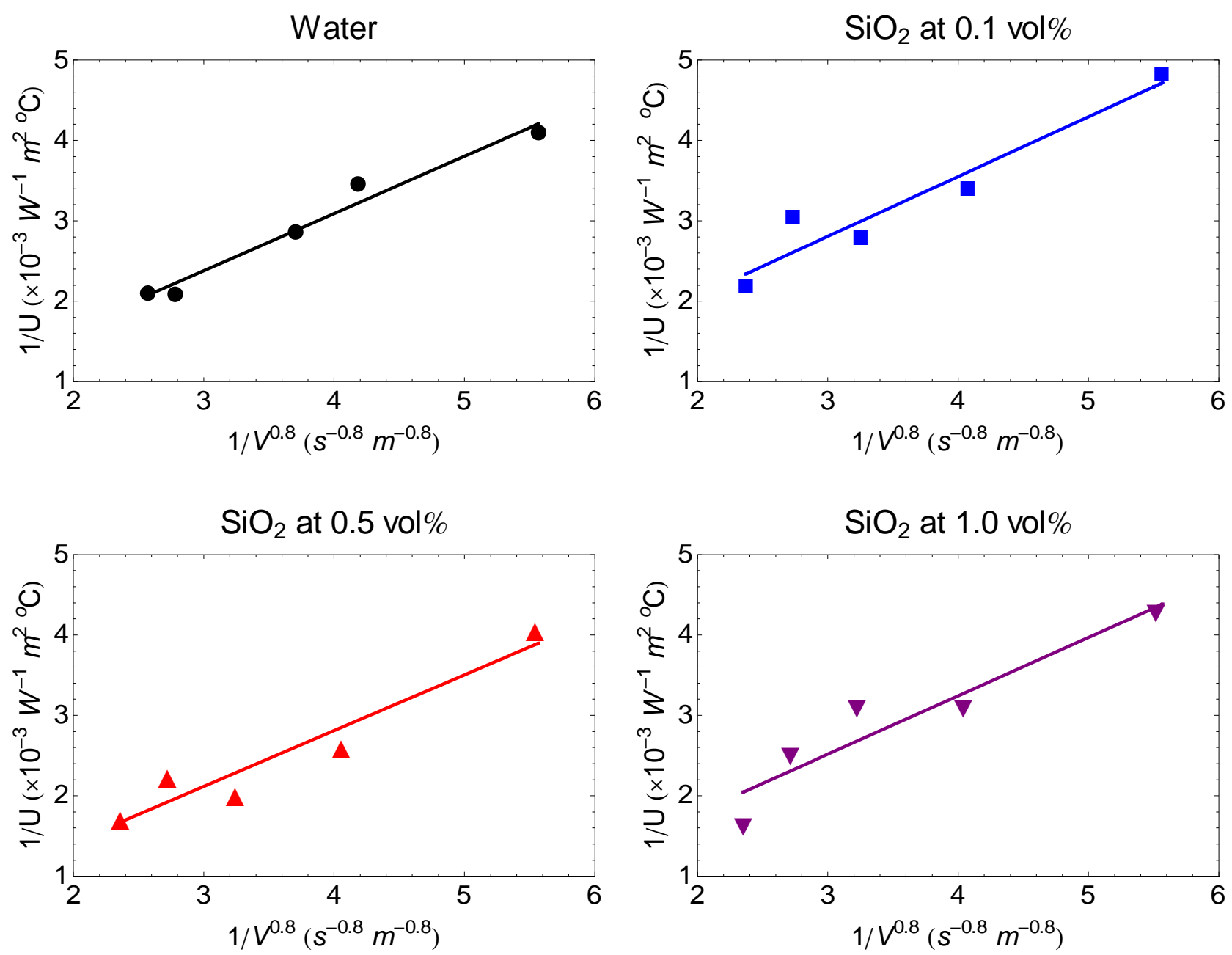

Figure 3 Plots of $1 / U$ vs $1 / V^{0.8}$ for $\mathrm{SiO}_{2}$ nanofluids and water. Note, the straight lines are the linear fittings to the experimental data points. 


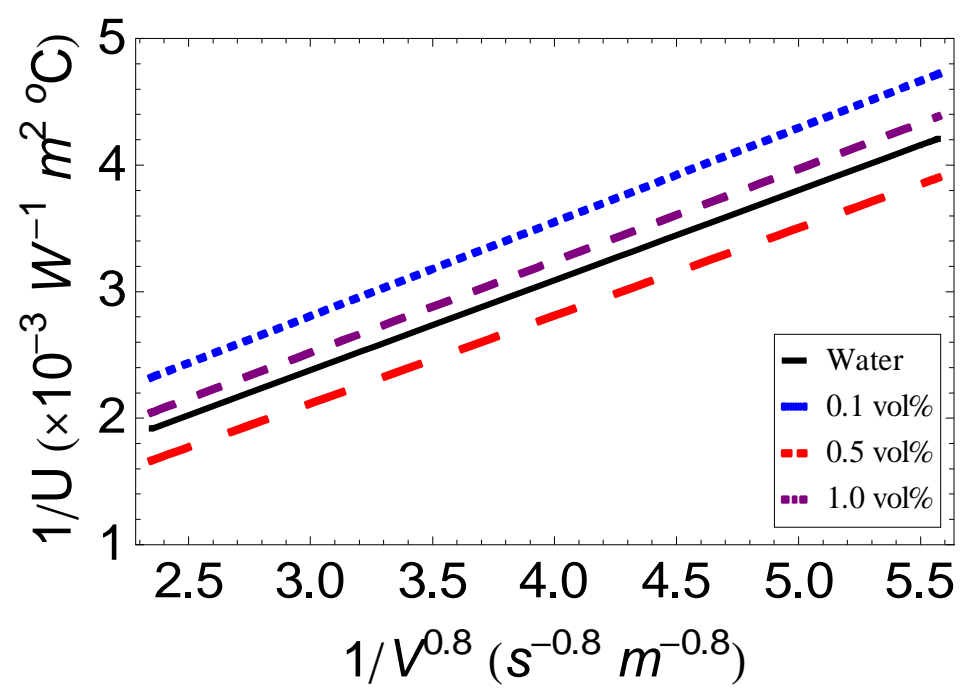

Figure 4 Comparison of the linear fittings of $1 / U$ vs $1 / V^{0.8}$ for $\mathrm{SiO}_{2}$ nanofluids and water. 


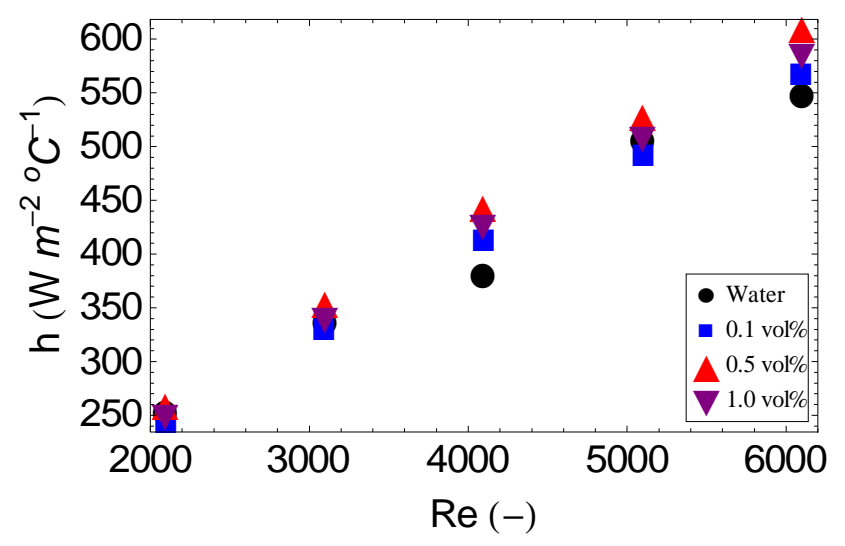

(a)

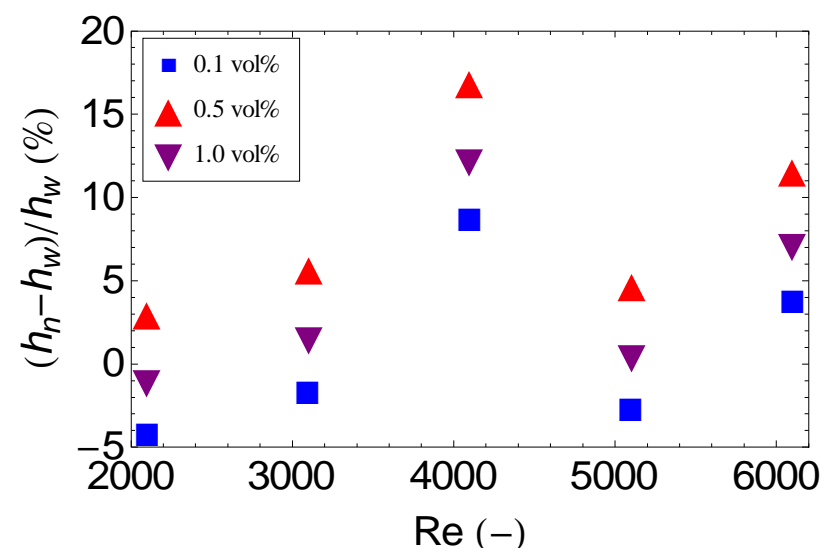

(b)

Figure 5 (a) Calculated heat transfer coefficients for water and $\mathrm{SiO}_{2}$ nanofluids for different Reynolds numbers and (b) the percentage of the change of $\mathrm{CHTC}$ of $\mathrm{SiO}_{2}$ nanofluids to that of water. 

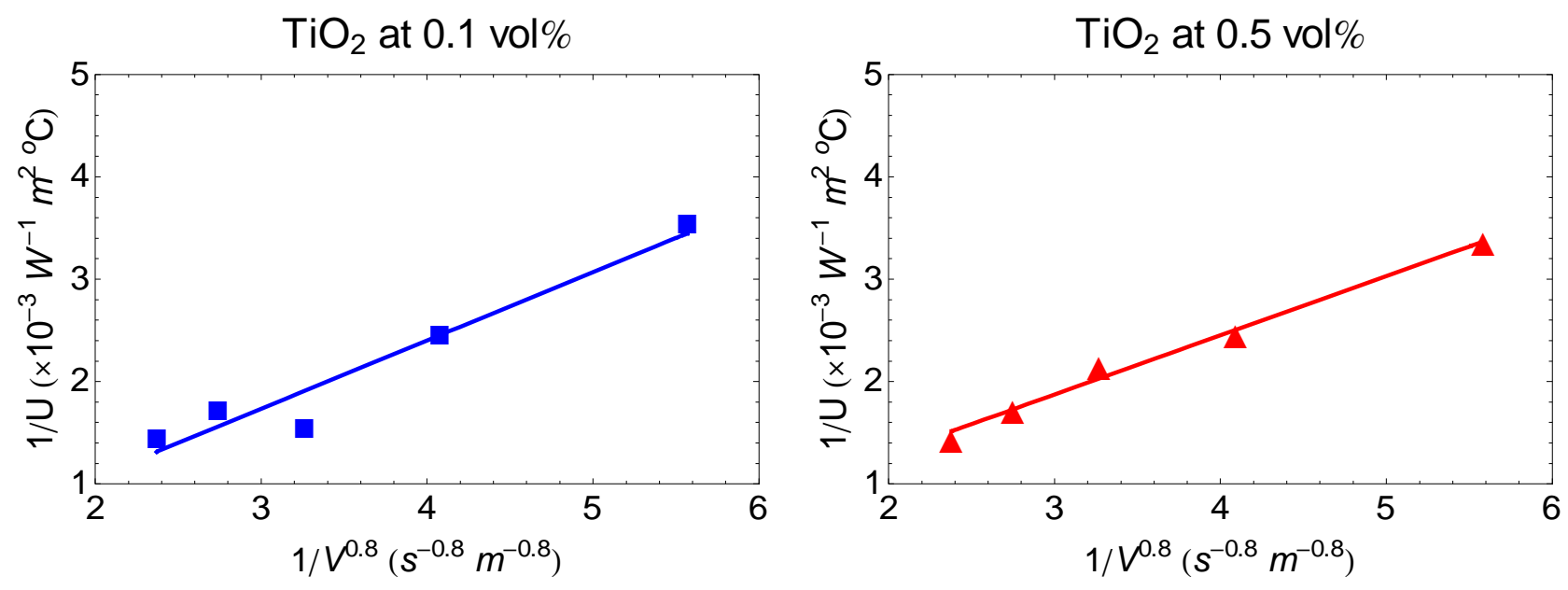

$\mathrm{TiO}_{2}$ at 1.0 vol $\%$
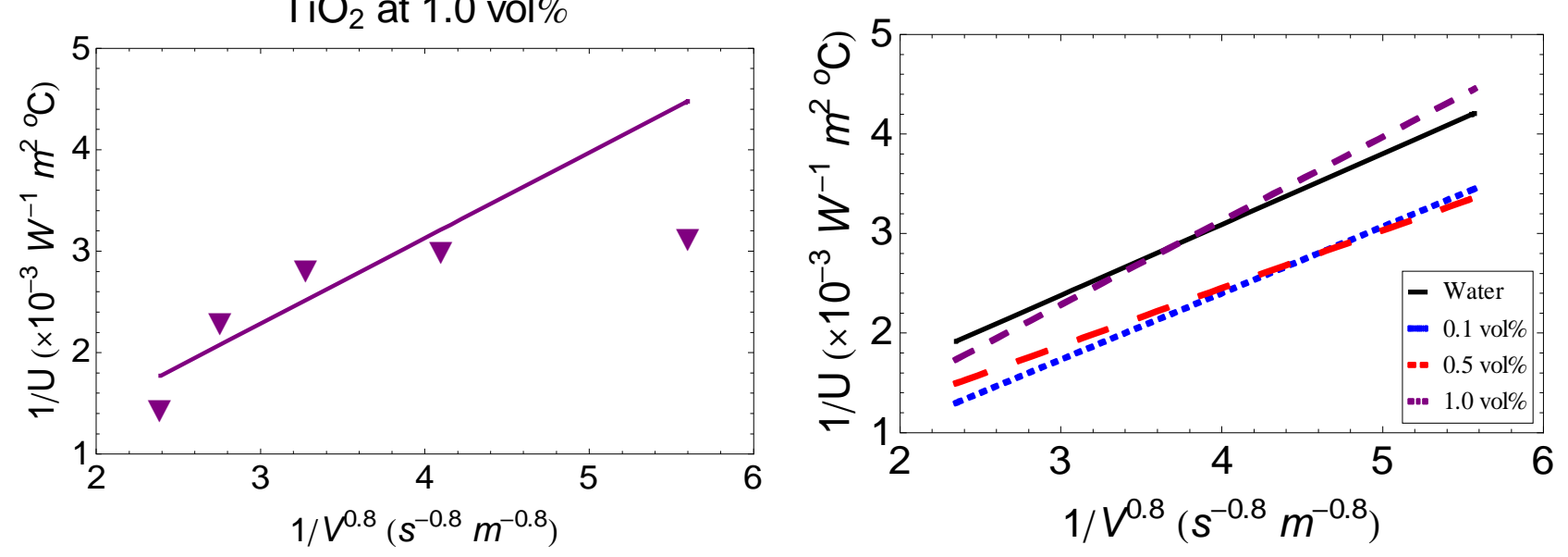

Figure 6 The linear fittings of $1 / U$ vs $1 / V^{0.8}$ for $\mathrm{TiO}_{2}$ nanofluids at $0.1 \mathrm{vol} \%, 0.5 \mathrm{vol} \%$ and $1.0 \mathrm{vol} \%$, the graph on the bottom right is the comparison of these linear fittings. 


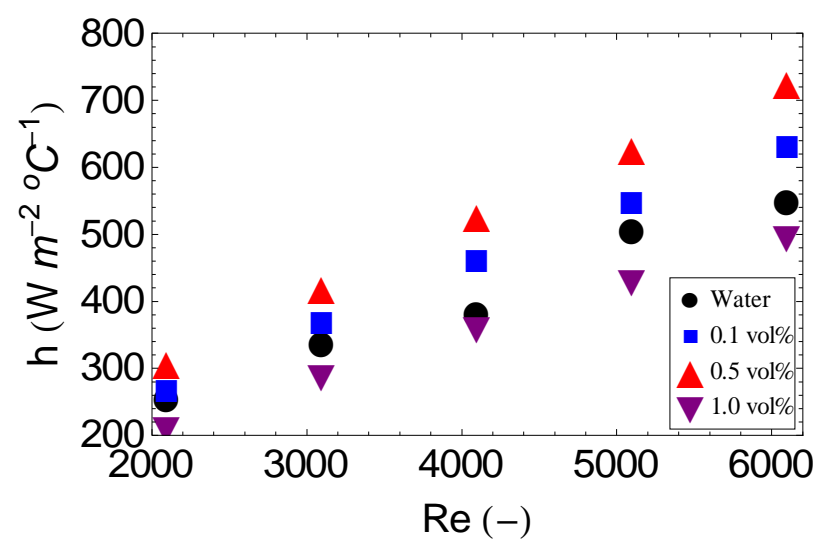

(a)

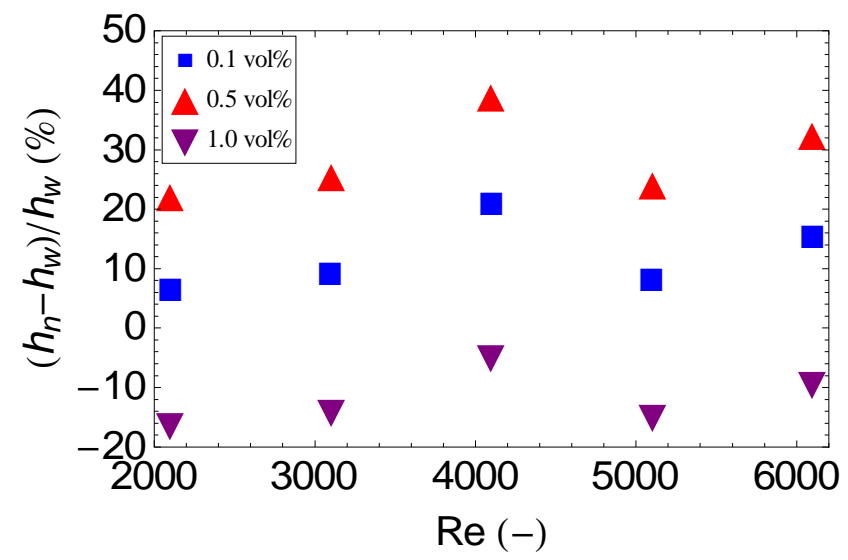

(b)

Figure 7 (a) Calculated heat transfer coefficients for water and $\mathrm{TiO}_{2}$ nanofluids for different

Reynolds numbers and (b) the percentage of the change of $\mathrm{CHTC}$ of $\mathrm{TiO}_{2}$ nanofluids to that of water. 

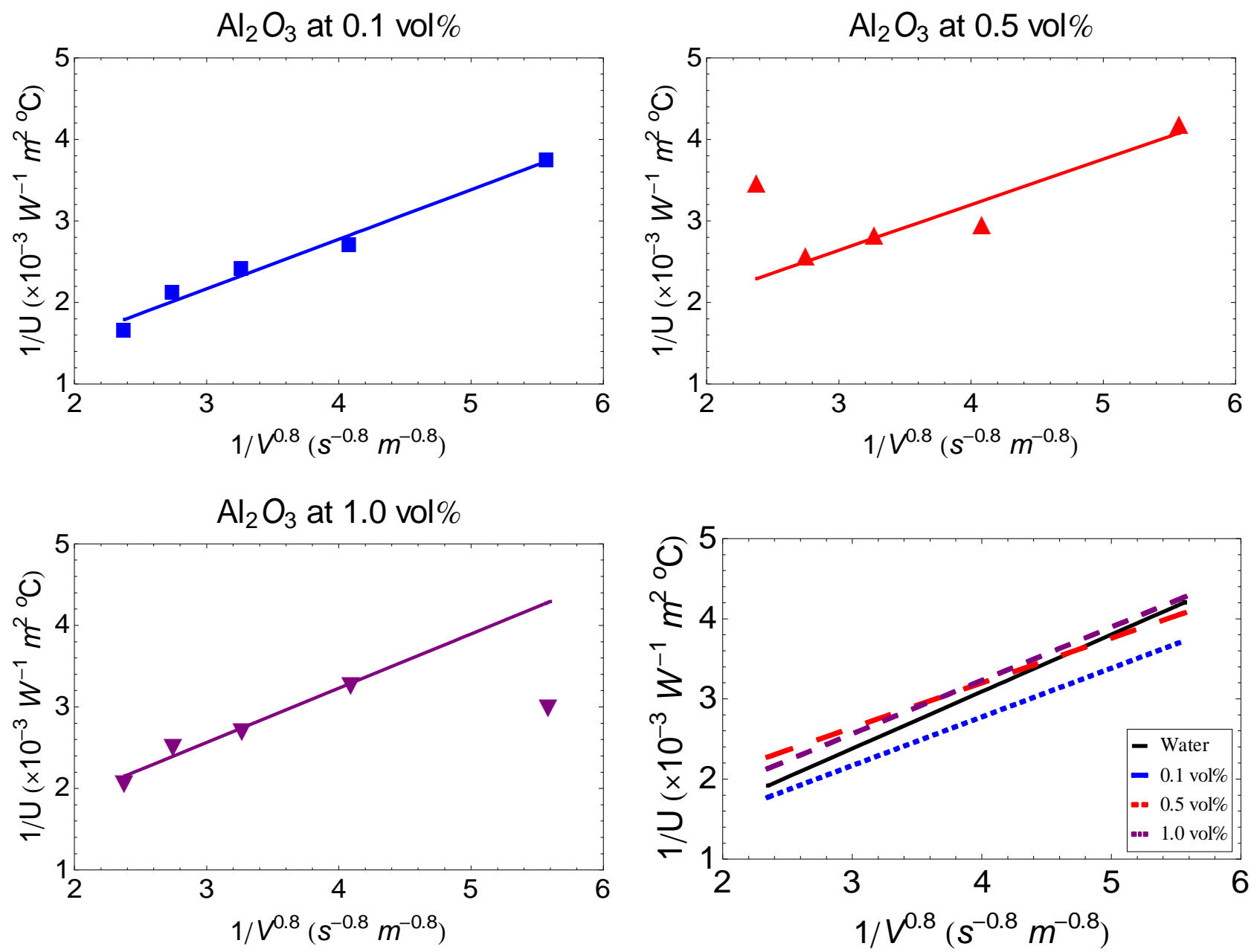

Figure 8 The linear fittings of $1 / \mathrm{U}$ vs $1 / \mathrm{V}^{0.8}$ for $\mathrm{Al}_{2} \mathrm{O}_{3}$ nanofluids at $0.1 \mathrm{vol} \%, 0.5$ vol\% and 1.0 vol\%, the graph on the bottom right is the comparison of these linear fittings. 


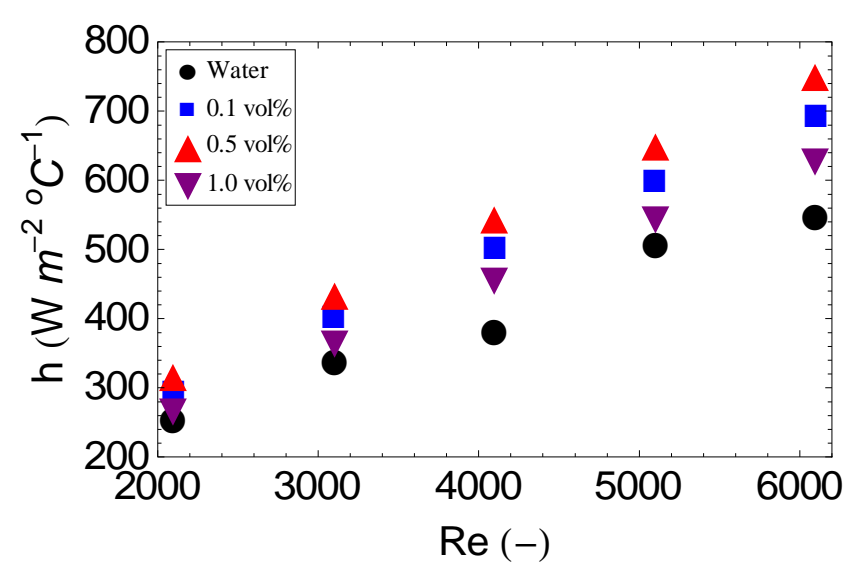

(a)

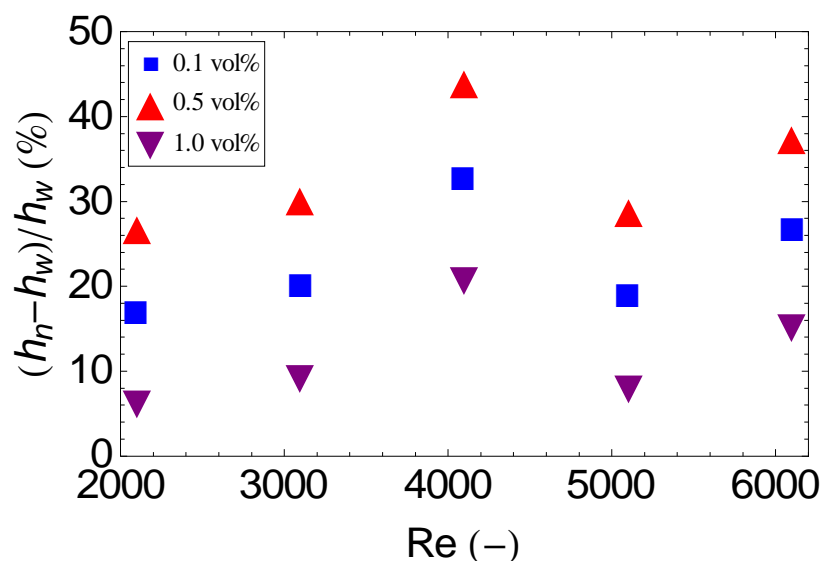

(b)

Figure 9 (a) Calculated heat transfer coefficients for water and $\mathrm{Al}_{2} \mathrm{O}_{3}$ nanofluids for different

Reynolds numbers and (b) the percentage of the change of CHTC of $\mathrm{Al}_{2} \mathrm{O}_{3}$ nanofluids to that of water. 


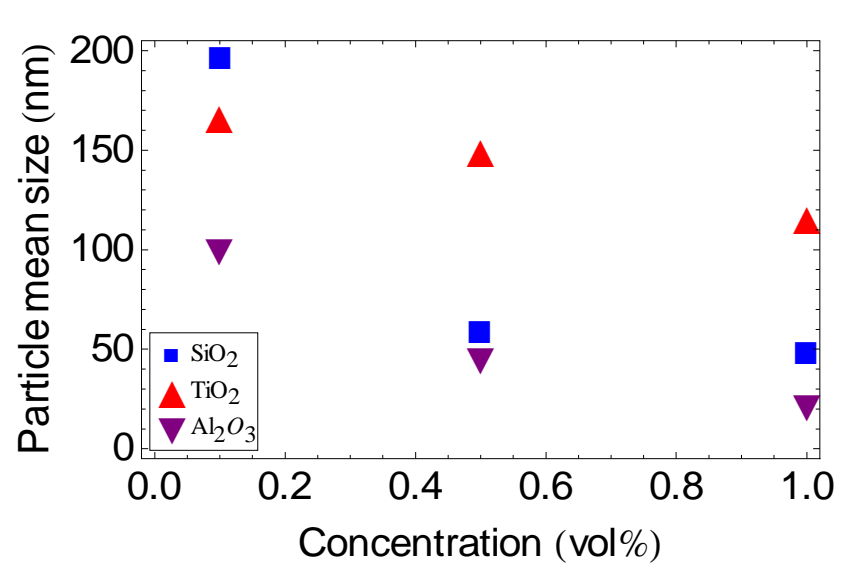

(a)

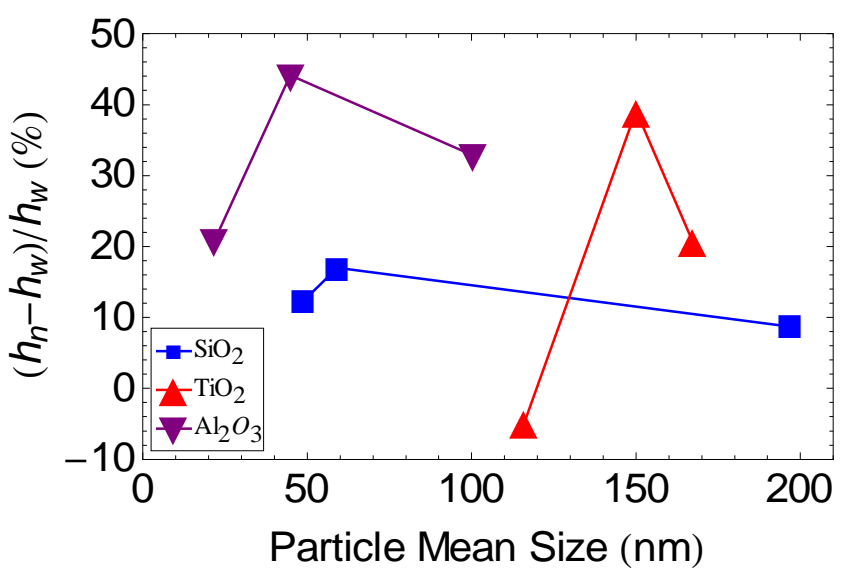

(b)

Figure 10 (a) Particle mean size vs concentration for $\mathrm{SiO}_{2}, \mathrm{TiO}_{2}$ and $\mathrm{Al}_{2} \mathrm{O}_{3}$ nanofluids and (b) the percentage of CHTC enhancement to water vs particle size at Reynolds number 4100. 


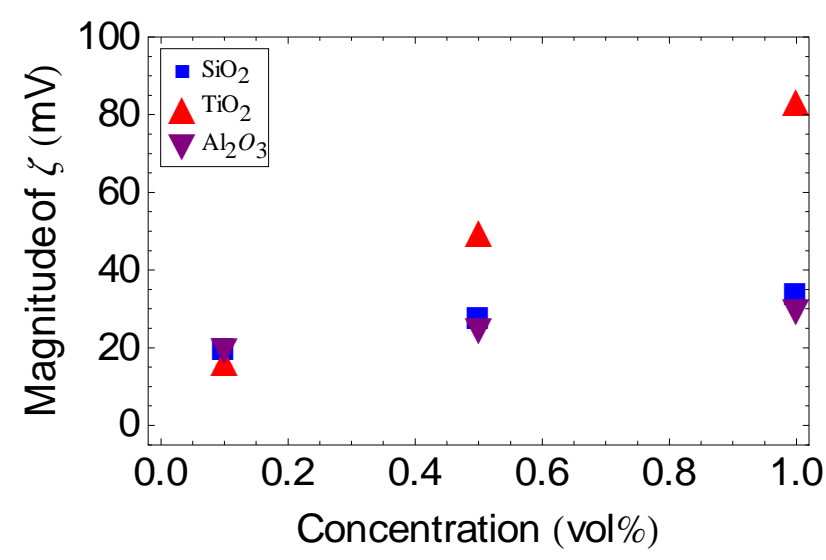

(a)

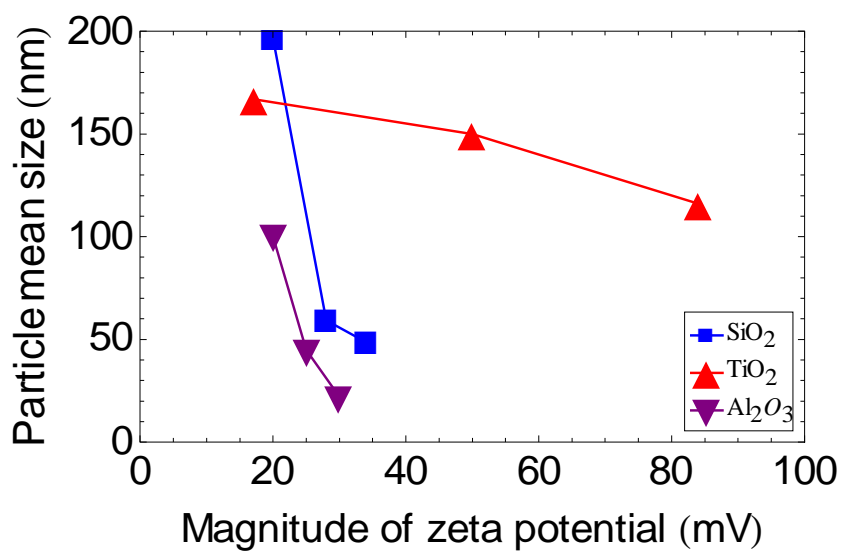

(b)

Figure 11 Magnitude of zeta potential vs (a) concentration and (b) particle mean size of the nanofluid samples. 